\title{
$\begin{array}{ll}\text { Research Square } & \text { Preprints are preliminary reports that have not undergone peer review. } \\ \text { They should not be considered conclusive, used to inform clinical practice, }\end{array}$ or referenced by the media as validated information. \\ Distinct Binding Mode of BAFF antagonist antibodies Belimumab and Tabalumab, analyzed by computer simulation
}

\section{Yaxin Jiang}

Tianjin University

Jian Sun ( $\square$ sunj@tju.edu.cn )

Tianjin University https://orcid.org/0000-0003-1749-6789

Jing Wei

Tianjin University

\section{Research Article}

Keywords: BAFF, belimumab, tabalumab, computation analysis, systemic lupus erythematosus

Posted Date: October 25th, 2021

DOI: https://doi.org/10.21203/rs.3.rs-974192/v1

License: (c) This work is licensed under a Creative Commons Attribution 4.0 International License.

Read Full License 


\title{
Distinct Binding Mode of BAFF antagonist antibodies Belimumab and Tabalumab, analyzed by computer simulation
}

\author{
Yaxin Jiang ${ }^{\dagger, a}$, Jian Sun ${ }^{*, a b}$, Jing Wei ${ }^{*, a}$
}

aTianjin Key Laboratory for Modern Drug Delivery \& High-Efficiency, School of Pharmaceutical Science and Technology, Tianjin University, No. 92 Weijin Road, Nankai District, Tianjin, 300072, P. R. China

${ }^{b}$ National Supercomputing Center in Tianjin, 3F, No.5 Building, TEDA Service Outsourcing Industrial Park, Binhai New Area, Tianjin, 300457, P. R. China

These authors contribute equally to this work

* Co-corresponding authors

Address correspondence to:

Jian Sun

Tianjin Key Laboratory for Modern Drug Delivery \& High-Efficiency, School of Pharmaceutical Science and Technology, Tianjin University

No. 92 Weijin Road, Nankai District, Tianjin, 300072, P. R. China

Tel: 86-22-87401943; Fax: 86-22-27892025

E-mail: sunj@tju.edu.cn

Address correspondence to:

Jing Wei

Tianjin Key Laboratory for Modern Drug Delivery \& High-Efficiency, School of Pharmaceutical Science and Technology, Tianjin University

No. 92 Weijin Road, Nankai District, Tianjin, 300072, P. R. China

E-mail: betty_wj@tju.edu.cn

\begin{abstract}
B-cell activating factor (BAFF) can binding to specific receptors and activate signaling pathways associated with $\mathrm{B}$ cell activation. Belimumab and tabalumab are anti-BAFF monoclonal antibodies, while belimumab was proved by FDA in 2011 as a targeted therapy for systemic lupus erythematosus (SLE) and showed better clinical effect than tabalumab. The combination modes of BAFF-belimumab complex and BAFF-tabalumab complex were simulated to better understand the reason for the difference of the inhibition effect between belimumab and tabalumab. The structures of belimumab and tabalumab were constructed by homology modeling. The combination mode of BAFF-belimumab complex was analyzed by molecular dynamics simulation, and the combination mode of BAFF-tabalumab complex was analyzed by protein-protein docking after molecular dynamics simulation. Both belimumab and tabalumab contacted with BAFF at the same hydrophobic center which the natural receptors of BAFF bind to. I51, F54, K58 D100, D101, L102, L103, P105 of belimumab heavy chain and R27, Y30,
\end{abstract}


K49, S65 of belimumab light chain contribute to the BAFF-belimumab interaction mainly by hydrogen bond, salt bridge and hydrophobic effect. More important, Belimumab could contact with L83 of BAFF and produced a steric hindrance with the adjacent BAFF trimers, while tabalumab could not. Belimumab had better clinical effect than tabalumab mainly because it could bind to L83 of BAFF and affect the formation of BAFF 60-mer, in addition to inhibition of the interaction of BAFF with its receptors.

Keywords: BAFF, belimumab, tabalumab, computation analysis, systemic lupus erythematosus 


\section{Introduction}

B-cell activating factor (BAFF, also known as BLyS, zTNF4, TNFSF13B, THANK, and TALL-1) is a member of the tumor necrosis factor (TNF) superfamily, and it can activate the signaling pathways by binding specific receptors[1-9]. BAFF is a type II transmembrane protein encoded by human chromosome 13q34, which is mainly expressed in peripheral blood mononuclear cells, lymph nodes, spleen, and thymus, but lowly expressed in the small intestine, pancreas, placenta, and lung[10, 11]. Abundant evidence demonstrated that BAFF is involved in pathogenesis of systemic lupus erythematosus (SLE), which is a prototype autoimmune disease affecting multiple organ systems[12-18]. In these patients, a large number of autoantibodies are produced and the deposition of immune complexes occurs in multiple organs, especially in kidneys[19-26].

BAFF and BAFF is not only biologically activated as a membrane bound protein, but also found in soluble form[27-29]. The soluble BAFF (sBAFF) is formed from the hydrolysis of membrane-type BAFF and can improve the activity of B cells, CD4+T cells, and NK cells to increase the body's immune responses[30]. Three kinds of the receptors of BAFF have been reported, they are B-cell maturation antigen (BCMA), BAFF receptor 3 (BR3), and trans-membrane activator and calcium modulator and cyclophilin ligand interactor (TACI)[2, 31-41]. Although BAFF often functions as a homo-trimer form, a more active BAFF 60-mer has been reported[42]. Twenty soluble BAFF trimers oligomerize into 60-mer through trimer-trimer interaction via a long DE loop (KVHVFGDELS), and this 60-mer is considered to be more active than trimer because the clustering of receptors on the B-cell surface[43, 44]. Since BAFF can bind to B lymphocytes, induce their proliferation, differentiation, and secretion of immunoglobulins [45, 46], and some researches showed that the elevated levels of BAFF are closely related to SLE activity[26], BAFF and its downstream signal transduction factors become ideal targets for the treatment of autoimmune diseases.

Antibodies targeting BAFF can inhibit the proliferation and activation of B cells by blocking the binding of BAFF and its receptors[47]. Anti-BAFF monoclonal antibody can reduce the elevated levels of immunoglobulin and lupus related damage factors in peripheral blood of SLE patients[48]. Belimumab (also known as Benlysata) is a fully human monoclonal IgG1 $\lambda$ antibody, which can neutralize the soluble BAFF[12, 49-55]. It was proved by FDA in 2011 as a targeted therapy for SLE[56-58]. Clinical trials of SLE patients with belimumab has shown decreased the number of circulating naive B cells, activated B cells, and enhanced clinical efficacy[48, 59, 60]. Tabalumab (formerly LY2127399) is a fully human IgG4 monoclonal antibody. Same as natural BAFF 
receptors, tabalumab binds both membrane-bound and soluble BAFF, while belimumab binds only soluble BAFF[61, 62].

Tabalumab reduced rheumatoid arthritis (RA) signs and symptoms in subjects naive to biological disease-modifying antirheumatic drugs (bDMARDs) such as TNF inhibitors in an initial dose-ranging study[63]. Telitacicept is a fusion protein constructed from the extracellular part of TACI and Fc part of human IgG1. TACI has a strong affinity for BAFF and A proliferation-inducing ligand (APRIL), a typical type II membrane protein that can stimulate B cell proliferation and tumor cell growth[64, 65]. Therefore, Telitacicept can block the interaction of BAFF and APRIL with their receptors to block the biological activities of BAFF and APRIL. This double-blocking effects may be more effective than blocking BAFF alone, and can block the proliferation of B lymphocytes and treat autoimmune diseases more effectively. On March 12, 2021, Telitacicept was approved by China National Medical Products Administration (NMPA).

In this study, we employed homology modeling, molecular docking, and molecular dynamics (MD) simulation to develop three dimensional (3D) structural model of BAFF-belimumab complex, in order to understand the interaction mechanism of belimumab in atomic detail. After that, we calculated the binding free energy and energy decomposition to each residue to figure out the binding mechanism and alanine mutational analyses to validate our findings. Then we built 3D structure model of tabalumab and performed MD simulation for BAFF-tabalumab complex, to figure out the reason why tabalumab failed in clinical trial[66]. These results give insights into the interaction mechanism between BAFF and its antibody antagonists, and further provide foundation for designing novel BAFF-targeted inhibitors in future.

\section{Material and methods}

\subsection{Construction of Molecular Systems for BAFF and Belimumab}

The 3D crystal structure of BAFF in complex with belimumab was downloaded from the website of Protein Data Bank (http://www.rcsb.org/) with an access code of 5Y9J. Due to a breakpoint in downloaded 3D structure (S136 to G142 in heavy chain), continuous peptides structure of heavy chain was constructed by SWISS-MODEL (https://swissmodel.expasy.org/) using downloaded structure as template. To build BAFF-belimumab complex, the constructed heavy chain of belimumab were matched to downloaded complex by Chimera Ver1.14. 


\subsection{Energy Minimization and MD Simulation of BAFF-Belimumab Complex}

During the process of molecular dynamics simulation, after building the starting structure, a simulation was carried out to obtain an equilibrated system which is completed structure optimization and energy minimization. The SANDER module of the AMBER 16 package with the AMBER parm99SB force field was used[67]. Counter ions were added to neutralize the charge for the system. TIP3P water box was set to a truncated octahedron periodic box functioning as a kind of solvent to make the system be infiltrated in whose size is $1 \mathrm{~nm}$. Generally, the Particle Grid Ewald (PME) method was used to deal with long-range electrostatic interactions $[68,69]$. The SHAKE algorithm which supports atomic vibration in quantum mechanical calculation simulation system was applied to fix all of the covalent bonds. In the simulation, $0.8 \mathrm{~nm}$ referring to the cutoff distance was set up when there were the nonbonded interactions[70].

The solvated system which has performed energy minimization was conducted MD simulation. The water-solvent molecules and ions were optimized first while the atoms of the residues of the complex were restrained. Then, for all residues, keep the main chain residues frozen while relaxing the side chains. Finally, all atoms were allowed to move freely. 2 fs was set up for each integration step and the ensemble type was set to NPT (a kind of isothermal isobaric system). The steepest descent method was executed to go on the energy minimization for the first 5000 steps. Then, the conjugated gradient method was used for the subsequent 2500 steps.

The temperature was controlled from $0 \mathrm{~K}$ to $300 \mathrm{~K}$ within the period of $100 \mathrm{ps}$ after the structure was minimized to continue the MD simulation. And the systems were equilibrated in the NPT ensemble ( 1 atm and $300 \mathrm{~K}$ ) for $100 \mathrm{ps}$ when the proteins were kept frozen. Next, the complexes were equilibrated for $500 \mathrm{ps}$ without restraint. At last, the whole system was subject to $200 \mathrm{~ns}$ Molecular Dynamics under the above NPT ensemble. The PTRAJ module can be used to collect atomic coordinates of the system in detail.

\subsection{Binding Free Energy Calculation on BAFF-Belimumab System and Per-Residue Free Energy Decomposition Analysis}

After MD simulation, the interactions of the protein complex system were confirmed. The validations were conducted by calculating the binding free energy and decomposing the binding free energy into per residues. The molecular mechanics MM-GBSA algorithms in AMBER 16 were implemented to calculate the binding free energies between BAFF and belimumab. The total binding free 
energies in condensed phase can be calculated by the following formula:

$$
\begin{gathered}
\Delta G_{\text {bind }}=\Delta E_{M M}+\Delta G_{\text {sol }}-T \Delta S \\
\Delta E_{M M}=\Delta E_{\text {ele }}+\Delta E_{v d w}+\Delta E_{\text {int }} \\
\Delta G_{\text {sol }}=\Delta G_{\text {polar }}+\Delta G_{N P}
\end{gathered}
$$

Where $\Delta G_{\text {bind }}$ is the binding free energy in solution state, $\Delta E_{M M}$ is the molecular mechanics energy which is consisted by an electrostatic interaction $\left(\Delta E_{\text {ele }}\right)$, a van der Waals interaction $\left(\Delta E_{v d w}\right)$ and an internal energy $\left(\Delta E_{\text {int }}\right)$ for a ligand or a protein. $\Delta G_{\text {sol }}$ is the solvation free energy, consisted by a polar component $\left(\Delta G_{\text {polar }}\right)$ and a nonpolar one $\left(\Delta G_{N P}\right) . \Delta G_{p o l a r}$ can be calculated by GB method[71]. $\Delta G_{N P}$ is calculated by the solvent-accessibility surface area (SASA) equation $\Delta G_{N P}=\gamma S A S A+\beta$, where SASA can be obtained from the MSMS program, and the values of $\gamma$ and $\beta$ were set as $0.72 \mathrm{kcal} /\left(\mathrm{mol}^{*} \mathrm{~nm}^{2}\right)$ and $0.00 \mathrm{kcal} / \mathrm{mol} \mathrm{respectively}$. A mount of studies showed that entropy does not contribute much to the relative binding free energies[72].

The free binding energy decomposition of residue-inhibitor interaction for each of BAFF and belimumab residues can also be calculated by alanine mutation. The free energy changes $\left(\Delta \Delta G_{\text {bind }}\right)$ were estimated by comparing the delta free energy of the wild type $\left(\Delta G_{W T}\right)$ with the delta free energy of alanine mutant $\left(\Delta G_{m u t}\right), \Delta \Delta G_{\text {bind }}=\Delta G_{W T}-\Delta G_{m u t}$, A negative $\Delta \Delta G_{\text {bind }}$ indicates that the wild type protein is more favorable as the $\Delta G_{W T}$ is more negative, and the opposite is true.

\subsection{Construction of BAFF-Tabalumab Complex}

Due to the absence of 3D structure of tabalumab, we constructed 3D structure of tabalumab by SWISS-MODEL using 4NPY for heavy chain and 5WT9 for light as template which were recommended by search template results. The constructed 3D structure of tabalumab was performed MD simulation using the same parameters as BAFF-belimumab complex to attain stable structure with low energy. Finally, the interaction between BAFF and tabalumab was analyzed by Chimera Ver1.14. 


\section{Results and Discussion}

\subsection{Homology Construction of BAFF-Belimumab System}

Homologous construction was done by SWISS-MODEL to smooth the remedy of the break point. To rank the constructed structure,

Ramachandran plots were calculated to assess the geometric properties of the backbone conformations of it. $100 \%$ of the residues fall within the most favored region for both chains of belimumab. The constructed system was further refined by performing an optimized geometry calculation of the mechanics using the SANDER module.

\subsection{Simulation and Free Binding Energy Calculation}

To ensure the proper conformational space sampling, we performed a $200 \mathrm{~ns}$ MD simulation for the BAFF-belimumab complex.

The atomic Root Mean Square Deviation (RMSD) fluctuations of the backbone atoms (CA, C and N atoms) of BAFFs and Belimumabs were separately calculated and outlined into a function of time (Fig. 1).

It can be concluded that the BAFF and two chains of belimumab have relatively smooth curves in the last 20 ns period with the average RMSD values of $0.200 \mathrm{~nm}$ for heavy chain, $0.127 \mathrm{~nm}$ for light chain of belimumab and $0.135 \mathrm{~nm}$ for BAFF. The system becomes equilibrated as judged by RMSDs.

The individual energy terms of the binding free energies of the BAFF-belimumab complex were calculated by the MM-GBSA method. Different terms of energy values are listed in Table 1. The enthalpy of the BAFF-belimumab complex was estimated at $48.68 \mathrm{kcal} / \mathrm{mol}$ by the MM-GBSA approach.

Table 1 The binding free energies of the BAFF-belimumab complex $(\mathrm{kcal} / \mathrm{mol})$

\begin{tabular}{|c|c|c|c|c|c|c|c|c|}
\hline \multirow{2}{*}{ Component* } & \multicolumn{2}{|c|}{ Complex } & \multicolumn{2}{|c|}{ BAFF } & \multicolumn{2}{|c|}{ Belimumab } & \multicolumn{2}{|c|}{ Delta } \\
\hline & Mean & STD. & Mean & STD. & Mean & STD. & Mean & STD. \\
\hline$E_{v d w}$ & -4317.95 & 26.25 & -3153.03 & 20.69 & -1073.85 & 11.75 & -91.07 & 6.11 \\
\hline$E_{\text {ele }}$ & -40584.57 & 101.12 & -29863.14 & 92.27 & -10345.54 & 43.09 & -375.89 & 18.17 \\
\hline$E_{\text {int }}$ & 0 & 0 & 0 & 0 & 0 & 0 & 0 & 0 \\
\hline$G_{\text {polar }}$ & -5867.00 & 74.46 & -4236.61 & 76.49 & -2061.96 & 36.20 & 431.57 & 14.1 \\
\hline$G_{N P}$ & 180.05 & 2.36 & 138.72 & 1.74 & 54.62 & 0.82 & -13.29 & 0.55 \\
\hline$E_{M M}$ & -44902.52 & 99.74 & -33016.17 & 89.87 & -11419.39 & 41.77 & -466.96 & 15.65 \\
\hline$G_{\text {sol }}$ & -5686.95 & 73.44 & -4097.89 & 76.00 & -2007.34 & 36.12 & 418.28 & 14.04 \\
\hline Total & -50589.47 & 63.97 & -37114.06 & 52.17 & -13426.73 & 28.69 & -48.68 & 4.09 \\
\hline
\end{tabular}

$* E_{v d w}$ : the van der Waals contribution from molecular mechanics; $E_{e l e}$ : the electrostatic energy as calculated by the molecular mechanics force field; $G_{\text {polar }}$ : the electrostatic energy to the solvation free energy; $G_{N P}$ : the energy of nonpolar components contributing to the solvation free energy; $E_{M M}$ : the free energy of the complex in vacuum which equals to $E_{v d w}, E_{\text {ele }}$ and $E_{\text {int }} ; G_{\text {sol }}$ : the free energy of the complex in solvation 
states which equals to $G_{p o l a r}$ and $G_{N P}$; Total: the whole binding free energy including $E_{M M}$ and $G_{s o l}$; Delta: the sum of BAFF and belimumab minus complex

In order to identify which of the interaction have a significant impact on the system, the binding free energy was divided into polar and nonpolar interactions. It was clear that the nonpolar interaction function as the dominant force, and the polar energy provided an unfavorable contribution for the formation of BAFF-belimumab complex by comparing values of the two types of energy. The absolute value of the nonpolar energy is about twice as much as the polar one. In addition, the polar interaction in the gas phase provided a favorable energy component, but it is mainly unfavorable in the solution phase.

In order to confirm the binding ability of belimumab and BAFF, the $\Delta G_{\text {bind }}$ of belimumab-BAFF complex and the complex of BAFF and a natural receptor BCMA were compared (Table 2). Our study only simulated the interaction between belimumab and a single chain of BAFF, while the previous study simulated the interaction between BAFF trimer and BCMA as a result, we divided the previous binding energy data by three to compare them. It showed that nonpolar force contributes to the complex binding much more for both two systems, this is consistent with the interaction between BAFF and its other natural receptors we reported before[70, 73]. Compared with the natural receptor BCMA, the binding energy of belimumab with BAFF is higher in absolute value, which means that Belimumab-BAFF complex interact more strongly and bind more closely with each other. It is the reason why belimumab can inhibit the binding of BAFF and their natural receptors and the function of the belimumab binding with BAFF to inhibit the function of BAFF can be realized.

Table 2 The comparison of binding energies between belimumab-BAFF complex and BCMA-BAFF complex (kcal/mol)

\begin{tabular}{ccc}
\hline Energy & Belimumab-BAFF & BCMA-BAFF \\
\hline$\Delta E_{v d w}$ & -91.07 & -63.96 \\
$\Delta E_{\text {ele }}$ & -375.89 & -94.23 \\
$\Delta E_{\text {int }}$ & 0 & 0 \\
$\Delta G_{\text {polar }}$ & 431.57 & 123.09 \\
$\Delta G_{N P}$ & -13.29 & -10.13 \\
$\Delta E_{M M}$ & -466.96 & -158.19 \\
$\Delta G_{\text {sol }}$ & 418.28 & 112.96 \\
$\Delta G_{\text {bind }}$ & -48.68 & -45.23 \\
\hline
\end{tabular}

\subsection{The Binding Mode Between BAFF and Belimumab}

To figure out the binding site and interact mechanism, we analyzed the binding mode between BAFF and belimumab (Fig. 2). BAFF can interact with both heavy and light chain of belimumab mainly by hydrophobic effect, hydrogen bond and salt bridge. The major binding site comprised of eight residues (I51, F54, K58, D100, L101, L102, L103 and P105) in the heavy chain of belimumab. The 
hydrophobic part of belimumab heavy chain was in close contact with Y65, L70, 192 and P123 of BAFF and heavy K58/BAFFE 125 and heavy $100 /{ }_{\text {BAFF }} 124$ formed salt bridge, respectively (Fig. 2a).

BAFF formed three hydrogen bonds with the light chain of belimumab, they are formed by backbone of light 227 with backbone of BAFF $\mathrm{S} 85$, hydroxyl of light $\mathrm{S} 65$ with backbone of ${ }_{\text {BAFF }}$ G80, backbone of light G93 with backbone of ${ }_{\text {BAFF }}$ S21. K49 of belimumab light chain and D81 of BAFF formed salt bridge, and the hydrophobic effect of the light chain and BAFF is mainly existed by Y30 of light chain and L83 of BAFF (Fig. 2b).

\subsection{The Binding Free Energy Decomposition of Per Residue and Computational Alanine Scanning}

To further analyze the binding mechanism, binding free energy decomposition was performed into a per-residue contribution spectrum. The criterion of $\left|\Delta G_{\text {bind }}\right|>1 \mathrm{kcal} / \mathrm{mol}$ was employed to identify the important residues which make contributions to the free energy. According to this standard, seven residues in heavy chain of belimumab (I51, F54, D100, D101, L102, L103 and P105), four residues in light chain of belimumab (R27, Y30, K49 and S65), and eight residues in BAFF (Y65, L70, G80, L83, L85, I92, P123 and R124) were selected. Total free energy of each key residue was illustrated as Fig. 3. For belimumab, D100 in heavy chain and K49 in light chain mainly provided electrostatic interaction, while the side chains of L101, L102 and L103 in heavy chain formed a hydrophobic site and mainly provided van der Waals interactions. These interaction results are consistent with our previous docking model, however, K58 of belimumab heavy chain and E125 was on the surface of protein, the desolvation step led to the decrease in the absolute value of binding energy although they formed salt bridge. The $\Delta G_{\text {bind }}$ value of heavy $\mathrm{K} 58$ and $\mathrm{BAFF}$ E125 was $-0.90 \mathrm{kcal} / \mathrm{mol}$ and $1.59 \mathrm{kcal} / \mathrm{mol}$, respectively. And the same situation existed in D81 of BAFF with the $\Delta G_{\text {bind }}$ value of 0.19 $\mathrm{kcal} / \mathrm{mol}$. The hydrogen bond interaction between G94 of belimumab light chain and G20 of BAFF was weak and unstable in MD simulation, which can be concluded by their $\Delta G_{\text {bind }}$ value of $-0.80 \mathrm{kcal} / \mathrm{mol}$ and $-0.82 \mathrm{kcal} / \mathrm{mol}$, respectively.

In order to confirm whether the side chain of specific residues plays an important role in the binding of BAFF-belimumab complex or not, seventeen residues were selected to perform the computational alanine scanning (Table 3). P105 of belimumab heavy chain, G80 and P123 of BAFF were not mutated into alanine because the significant skeleton structure will change when these side chains were replaced. In addition to R27 of belimumab light chain and L85 of BAFF, the binding energies of other residues become less 
negative after computational alanine scanning. It indicated that any one of these amino acids mutated to alanine would weaken the

binding affinity of BAFF-belimumab complex. Among these residues which had effect on the binding affinity, D100 of belimumab heavy chain and R214 of BAFF showed the largest $\Delta \Delta G_{\text {bind }}$ value, more than $21.48 \mathrm{kcal} / \mathrm{mol}$ and $16.66 \mathrm{kcal} / \mathrm{mol}$, respectively, which means that they played the most important role on the binding affinity. For both of them, the changes of electrostatic interactions contribute the most to their $\Delta \Delta G_{\text {bind }}$.

Table 3 The computational alanine scanning results of the key residues for the BAFF-belimumab complex (kcal/mol)

\begin{tabular}{cccccccc}
\hline Residue (chain) & $\Delta \Delta G_{v d w}$ & $\Delta \Delta G_{\text {ele }}$ & $\Delta \Delta G_{\text {polar }}$ & $\Delta \Delta G_{N P}$ & $\Delta \Delta G_{M M}$ & $\Delta \Delta G_{\text {sol }}$ & $\Delta \Delta G_{\text {bind }}$ \\
\hline I51 (heavy chain) & 1.75 & -0.14 & 8.53 & 0.23 & 1.61 & 8.75 \\
F54 (heavy chain) & 4.9 & 2.7 & 4.23 & 0.75 & 7.6 & 4.97 & 3.49 \\
D100 (heavy chain) & -2.2 & 37.1 & -4.61 & 0.28 & 34.9 & -4.33 & 21.48 \\
L101 (heavy chain) & 2.56 & 0.68 & 6.71 & 0.40 & 3.25 & 7.11 & 10.36 \\
L102 (heavy chain) & 8.18 & 0.04 & 5.26 & 1.05 & 8.21 & 6.3 & 5.43 \\
L103 (heavy chain) & 1.94 & 0.28 & 7.14 & 0.27 & 2.22 & 9.41 & -27.54 \\
R27 (light chain) & 2.89 & 34.02 & -27.88 & 0.35 & 36.91 & 0.29 \\
Y30 (light chain) & 2.77 & -2.72 & 11.82 & 0.41 & 0.05 & 12.23 & 3.19 \\
K49 (light chain) & 0.74 & 129.16 & -119.1 & 0.67 & 129.9 & -118.44 & 2.37 \\
S65 (light chain) & 0.12 & 3.25 & 9.07 & 0.15 & 3.36 & 9.22 & 3.50 \\
Y65 (BAFF) & 7.04 & 2.55 & 5.01 & 1.04 & 9.58 & 6.05 & 6.55 \\
L70 (BAFF) & 2.76 & 0.1 & 7.71 & 0.37 & 2.85 & 8.08 & 1.85 \\
L83 (BAFF) & 7.15 & -0.46 & 6.42 & 0.84 & 6.68 & 7.26 & 4.86 \\
L85 (BAFF) & 1.51 & 0.27 & 7.79 & 0.21 & 1.78 & 7.99 & 0.69 \\
I92 (BAFF) & 2.12 & -0.07 & 7.95 & 0.35 & 2.05 & 8.3 & 1.26 \\
R124 (BAFF) & 1.22 & 35.35 & -14.13 & 3.31 & 36.57 & -10.83 & 16.66 \\
E125 (BAFF) & 0.85 & 120.52 & -110.97 & 0.55 & 121.37 & -110.43 \\
\hline
\end{tabular}

$\Delta \Delta G_{\text {bind }}=\Delta G_{\text {bind }}($ alanine mutant $)-\Delta G_{\text {bind }}($ wild type $)$

$\Delta \Delta G_{\text {bind }}=\Delta \Delta G_{M M}+\Delta \Delta G_{\text {sol }}$

$\Delta \Delta G_{M M}=\Delta \Delta G_{\text {ele }}+\Delta \Delta G_{v d w}+\Delta \Delta G_{\text {int }}$

$\Delta \Delta G_{\text {sol }}=\Delta \Delta G_{\text {polar }}+\Delta \Delta G_{N P}$

\subsection{The Comparison of Binding Mode Between BAFF-Tabalumab Complex, BAFF-Belimumab Complex and BAFF-BR3 Complex}

The constructed tabalumab could interact with BAFF mainly by heavy chain through hydrophobic effect, hydrogen bond and salt bridge. BAFF formed two hydrogen bonds with the heavy chain of tabalumab, they are formed by heavy $\mathrm{N} 58$ with BAFFE125 and heavy $Y 100$ with backbone of ${ }_{\text {BAFF }}$ R124. In addition, DXL motif (D101, I102, L103) of tabalumab heavy chain is involved in binding with BAFF, heavy 101 and ${ }_{\text {BAFF }}$ R90 formed salt bridge. The hydrophobic effect of tabalumab and BAFF is mainly existed by I102, L103 of tabalumab heavy chain and L70, V86 of BAFF (Fig. 4).

As shown in Fig. 5, The hydrophobic center of BAFF was the active site which could contact with its natural receptors such as BCMA and BR3 at the DxL motif[74], and a structure similar to DxL motifs could also be found in CDR3 of heavy chains in both 
belimumab and tabalumab (Fig. 6). As a result, the mechanisms of inhibition of BAFF by belimumab and tabalumab were concerned

to be competitive inhibition with natural receptors.

It was reported that the dissolved BAFF trimer could combine to form a 60 -mer, and this 60 -mer was thought to be more active than BAFF trimer. In addition, L83 of BAFF is concerned that specifically contributes to the formation of BAFF 60-mer[75]. As a result, whether the antibody can interact with L83 of BAFF became the key point of the inhibition of BAFF. For BAFF-belimumab complex, the heavy chain of belimumab contact with L83 of BAFF by hydrophobic interaction. This hydrophobic effect brings the light chain close to BAFF, and causes hindrance that prevent the D loop of BAFF interact with adjacent BAFF homo-trimer, blocks the formation of BAFF 60-mer, and inhibit soluble BAFF more specifically and effectively compared with natural TNF receptors.

But for BAFF-tabalumab complex, the light of tabalumab could not combine with L83 of BAFF, so that no steric hindrance existed between the light chain of tabalumab and the adjacent BAFF trimer. As a result, tabalumab could not prevent the formation of BAFF $60 \mathrm{mer}$, and it seems to be the reason why tabalumab failed in clinical trials.

By alignment of the sequences of belimumab and tabalumab (Fig. 6), it is noted that R30 is in light CDR1 of tabalumab, instead of Y30 in belimumab. It is interesting that the difference in single amino acid of CDR1 make the two antibodies function differently. The amino acids corresponding to R27 in light CDR1 and G94 in light CDR3 could not be found in tabalumab, which made the light chain of tabalumab unable to form hydrogen bond with BAFF. Both the heavy CDR3 of belimumab and tabalumab had DxL motif. They could bind to the active site of BAFF and competitively inhibit the effect of BAFF, which showed that the heavy chain of belimumab and tabalumab had a similar mechanism in the process of inhibiting BAFF activity.

\section{Conclusions}

In summary, we successfully constructed the theoretical complex of BAFF with belimumab and tabalumab by homologous construction. The binding model between BAFF and belimumab was analyzed through MD simulation. The amino acids that played a key role in the interaction were determined, and the corresponding binding energy values were calculated through the energy decomposition. I51, F54, K58 D100, D101, L102, L103, P105 of belimumab heavy chain and R27, Y30, K49, S65 of belimumab light chain contribute to the BAFF-belimumab interaction mainly by hydrogen bond, salt bridge and hydrophobic effect. Both 
belimumab and tabalumab had a DxL motif which is the main binding site of the natural receptors with BAFF, and could function competitive inhibition with the natural receptors. The light chain of belimumab could contact with L83 of BAFF which is the key residue for the formation of BAFF 60-mer, and then the steric hindrance between belimumab light chain and adjacent BAFF trimers cause it unable to form BAFF 60-mer. Tabalumab contact with BAFF at the similar site as belimumab and the natural receptors while its light chain could not contact with L83 of BAFF, could not affect the formation of BAFF 60-mer and had a less inhibitory effect. Therefore, it is reasonable that belimumab showed better clinical therapeutic efficacies than Tabalumab and was approved by FDA for SLE in 2011. In summary, our computation studies may provide foundation for designing novel therapeutic antibodies in future. 


\section{*Declarations:}

Funding: This study was supported by the National Natural Science Foundation of China (Grant No.81273308).

Conflicts of interest/Competing interests: The authors declare no conflict of interest, financial or otherwise.

Availability of data and material: Not applicable.

Code availability: Not applicable.

Authors' contributions: Sun $\mathrm{J}$ and Wei J conceived and designed the experiments. Jiang $\mathrm{Y}$ performed the experiments. Wei J and Jiang Y analyzed the binding modes. Jiang Y and Sun J wrote the paper. All authors have read and approved the final manuscript to be published. 


\section{References:}

1. Afzali S, Salehi S, Shahi A, Esmaeili M, Farashi Bonab S, Peykari A, Bagherpour F, Ansaripour B, Soleimanian T, PourReza-Gholi F,Amirzargar A (2021) Investigating the Role of BAFF and Its Receptors in Renal Transplant Recipients with Chronic Antibody-Mediated Rejection. J Immunol Res 2021: 6654992. https://doi.org/10.1155/2021/6654992

2. Bakhuraysah MM, Theotokis P, Lee JY, Alrehaili AA, Aui PM, Figgett WA, Azari MF, Abou-Afech JP, Mackay F, Siatskas C, Alderuccio F, Strittmatter SM, Grigoriadis N,Petratos S (2021) B-cells expressing NgR1 and NgR3 are localized to EAE-induced inflammatory infiltrates and are stimulated by BAFF. Sci Rep 11(1): 2890. https://doi.org/10.1038/s41598$\underline{021-82346-6}$

3. Dechkhajorn W, Benjathummarak S, Glaharn S, Chaisri U, Viriyavejakul P,Maneerat Y (2020) The activation of BAFF/APRIL system in spleen and lymph nodes of Plasmodium falciparum infected patients. Sci Rep 10(1): 3865. https://doi.org/10.1038/s41598-020-60763-3

4. Eslami M, Meinl E, Eibel H, Willen L, Donze O, Distl O, Schneider H, Speiser DE, Tsiantoulas D, Yalkinoglu O, Samy E,Schneider P (2020) BAFF 60-mer, and Differential BAFF 60-mer Dissociating Activities in Human Serum, Cord Blood and Cerebrospinal Fluid. Front Cell Dev Biol 8: 577662. https://doi.org/10.3389/fcell.2020.577662

5. Schiemann B, Gommerman JL, Vora K, Cachero TG,Scott ML (2001) An Essential Role for BAFF in the Normal Development of B Cells Through a BCMA-Independent Pathway. Science 293(5537): 2111-2114.

6. Simon R, Diaz-Rosales P,Tafalla C (2021) The Ancient Cytokine BAFF- and APRIL-like Molecule Regulates the Functionality of Teleost $\operatorname{IgM}(+)$ B Cells Similarly to BAFF and APRIL. J Immunol 206(8): 1765-1775. https://doi.org/10.4049/jimmunol.2000762

7. Singhal A, Sashindran VK, Aggarwal A, Yadav AK,Kayastha S (2020) Utility of B Cell Activating Factor (BAFF) and a Proliferation induced Ligand (APRIL) Cytokines as Markers of Response to Anti-Tubercular Therapy. Journal of Clinical and Diagnostic Research. https://doi.org/10.7860/jcdr/2020/43605.13676

8. Thompson JS, Schneider P, Kalled SL, Wang L, Lefevre EA, Cachero TG, MacKay F, Bixler SA, Zafari M, Liu ZY, Woodcock SA, Qian F, Batten M, Madry C, Richard Y, Benjamin CD, Browning JL, Tsapis A, Tschopp J,Ambrose C (2000) BAFF binds to the tumor necrosis factor receptor-like molecule B cell maturation antigen and is important for maintaining the peripheral B cell population. J Exp Med 192(1): 129-135. https://doi.org/10.1084/jem.192.1.129

9. Vincent FB, Morand EF, Schneider P,Mackay F (2014) The BAFF/APRIL system in SLE pathogenesis. Nat Rev Rheumatol 10(6): 365-373. https://doi.org/10.1038/nrrheum.2014.33

10. Matsushita T,Sato S (2005) The role of BAFF in autoimmune diseases. Nihon Rinsho Meneki Gakkai Kaishi 28(5): 333342. https://doi.org/10.2177/jsci.28.333

11. Mukhopadhyay A, Jian N, Zhai YF, Yu GL,Aggarwal BB (1999) Identification and Characterization of a Novel Cytokine, THANK, aTNF Homologue That ActivatesApoptosis, Nuclear Factor- $\kappa B$, and c-Jun NH 2 -Terminal Kinase. Journal of Biological Chemistry 274(23): 15978-15981.

12. Birt JA, Wu J, Griffing K, Bello N, Princic N, Winer I, Lew CR,Costenbader KH (2020) Corticosteroid dosing and opioid use are high in patients with SLE and remain elevated after belimumab initiation: a retrospective claims database analysis. Lupus Sci Med 7(1). https://doi.org/10.1136/lupus-2020-000435

13. Hedrich CM (2017) Epigenetics in SLE. Curr Rheumatol Rep 19(9): 58. https://doi.org/10.1007/s11926-017-0685-1

14. Park E, Giles JT, Perez-Recio T, Pina P, Depender C, Gartshteyn Y, Askanase A, Bathon J,Geraldino-Pardilla L (2021) Hydroxychloroquine Use Is Not Associated With QTc Length in a Large Cohort of SLE and RA Patients. Res Sq. https://doi.org/10.21203/rs.3.rs-650818/v1

15. Theisen A, Bose P, Knight C,Oliver M (2020) Leukoencephalopathy and cerebral edema as the presenting manifestations of SLE in an ANA-negative adolescent female: A case report and review of literature.

16. Zhang D, Wang M, Shi G, Pan P, Ji J,Li P (2020) Regulating T Cell Population Alleviates SLE by Inhibiting mTORC1/C2 in MRL/lpr Mice. Front Pharmacol 11: 579298. https://doi.org/10.3389/fphar.2020.579298

17. Zhang M, Jie H, Wu Y, Han X,Sun E (2020) Increased MLKL mRNA level in the PBMCs is correlated with autoantibody production, renal involvement and SLE disease activity. Arthritis Research \& Therapy 22(1): 239. 

into the shared and distinct pathogenic immunity components of IgA nephropathy and SLE. Mol Genet Genomics 296(4): 1017-1026. https://doi.org/10.1007/s00438-021-01798-7

19. Aguiar R, Araujo C, Martins-Coelho G,Isenberg D (2017) Use of Rituximab in Systemic Lupus Erythematosus: A Single Center Experience Over 14 Years. Arthritis Care Res (Hoboken) 69(2): 257-262. https://doi.org/10.1002/acr.22921

20. Dörner T,Furie R (2019) Novel paradigms in systemic lupus erythematosus. The Lancet 393(10188): 2344-2358. https://doi.org/10.1016/s0140-6736(19)30546-X

21. Durcan L, O'Dwyer T,Petri M (2019) Management strategies and future directions for systemic lupus erythematosus in adults. The Lancet 393(10188): 2332-2343. https://doi.org/10.1016/s0140-6736(19)30237-5

22. Li Y, Higgs RE, Hoffman RW, Dow ER, Liu X, Petri M, Wallace DJ, Dorner T, Eastwood BJ, Miller BB,Liu Y (2019) A Bayesian gene network reveals insight into the JAK-STAT pathway in systemic lupus erythematosus. PLoS One 14(12): e0225651. https://doi.org/10.1371/journal.pone.0225651

23. Narain S,Furie R (2016) Update on clinical trials in systemic lupus erythematosus. Curr Opin Rheumatol $28(5)$ : $477-487$. https://doi.org/10.1097/BOR.0000000000000311

24. Scheinberg MA, Golmia AP, Golmia RP, de Souza Molotievschi RN,Dos Santos Cortada AP (2021) Lupus low disease activity (SLE) in patients treated with belimumab: a single-center real-life experience (2016-2019). Clin Rheumatol 40(3): 923-927. https://doi.org/10.1007/s10067-020-05315-w

25. Stohl W (2017) Inhibition of B cell activating factor (BAFF) in the management of systemic lupus erythematosus (SLE). Expert Rev Clin Immunol 13(6): 623-633. https://doi.org/10.1080/1744666X.2017.1291343

26. Vilas-Boas A, Morais SA,Isenberg DA (2015) Belimumab in systemic lupus erythematosus. RMD Open 1(1): e000011. https://doi.org/10.1136/rmdopen-2014-000011

27. Basta F, Mockel T, Petersohn J, Meineck M, Triantafyllias K, Engel S, Weinmann A, Luessi F, Weinmann-Menke J,Schwarting A (2021) The relationship between BAFF serum levels, anti-NMDAR autoantibodies and fatigue in patients with systemic lupus erythematosus and multiple sclerosis. Autoimmun Rev 20(5): 102802. https://doi.org/10.1016/j.autrev.2021.102802

28. Craxton A, Magaletti D, Ryan EJ,Clark EA (2003) Macrophage- and dendritic cell--dependent regulation of human B-cell proliferation requires the TNF family ligand BAFF. Blood 101(11): 4464-4471. https://doi.org/10.1182/blood-2002-10$\underline{3123}$

29. Karpusas M, Cachero TG, Qian F, Boriack-Sjodin A, Mullen C, Strauch K, Hsu YM,Kalled SL (2002) Crystal structure of extracellular human BAFF, a TNF family member that stimulates B lymphocytes. J Mol Biol 315(5): 1145-1154. https://doi.org/10.1006/jmbi.2001.5296

30. Shan X, Chen L, Cao M, Xu L,Zhang S (2006) Effects of human soluble BAFF synthesized in Escherichia coli on CD4+ and CD8+ T lymphocytes as well as NK cells in mice. Physiological Research 55(3): 301-307.

31. Alexaki VI, Notas G, Pelekanou V, Kampa M, Valkanou M, Theodoropoulos P, Stathopoulos EN, Tsapis A,Castanas E (2009) Adipocytes as immune cells: differential expression of TWEAK, BAFF, and APRIL and their receptors (Fn14, BAFF-R, TACI, and BCMA) at different stages of normal and pathological adipose tissue development. J Immunol 183(9): 5948-5956. https://doi.org/10.4049/jimmunol.0901186

32. Alexaki VI, Pelekanou V, Notas G, Venihaki M, Kampa M, Dessirier V, Sabour-Alaoui S, Stathopoulos EN, Tsapis A,Castanas E (2012) B-cell maturation antigen (BCMA) activation exerts specific proinflammatory effects in normal human keratinocytes and is preferentially expressed in inflammatory skin pathologies. Endocrinology 153(2): 739-749. https://doi.org/10.1210/en.2011-1504

33. Chiu A, Xu W, He B, Dillon SR, Gross JA, Sievers E, Qiao X, Santini P, Hyjek E, Lee JW, Cesarman E, Chadburn A, Knowles DM,Cerutti A (2007) Hodgkin lymphoma cells express TACI and BCMA receptors and generate survival and proliferation signals in response to BAFF and APRIL. Blood 109(2): 729-739. https://doi.org/10.1182/blood-2006-04$\underline{015958}$

34. Day ES, Cachero TG, Qian F, Sun Y,Whitty A (2005) Selectivity of BAFF/BLyS and APRIL for binding to the TNF family receptors BAFFR/BR3 and BCMA. Biochemistry 44(6): 1919-1931.

35. Gross JA, Johnston J, Mudri S, Enselman R,Clegg CH (2000) TACI and BCMA are receptors for a TNF homologue implicated in B-cell autoimmune disease. Nature 404(6781): 995-999. 

member BCMA (B cell maturation) associates with TNF receptor-associated factor (TRAF) 1, TRAF2, and TRAF3 and activates NF-kappa B, elk-1, c-Jun N-terminal kinase, and p38 mitogen-activated protein kinase. J Immunol 165(3): 13221330. https://doi.org/10.4049/jimmunol.165.3.1322

37. Lyu MA, Cheung LH, Hittelman WN, Marks JW, Aguiar RC,Rosenblum MG (2007) The rGel/BLyS fusion toxin specifically targets malignant B cells expressing the BLyS receptors BAFF-R, TACI, and BCMA. Mol Cancer Ther 6(2): 460-470. https://doi.org/10.1158/1535-7163.MCT-06-0254

38. Madry, Laabi, Callebaut, Roussel,Hatzoglou (1998) The characterization of murine BCMA gene defines it as a new member of the tumor necrosis factor receptor superfamily. International Immunology.

39. Marsters SA, Yan M, Pitti RM, Haas PE,Ashkenazi A (2000) Interaction of the TNF homologues BLyS and APRIL with the TNF receptor homologues BCMA and TACI. Current Biology Cb 10(13): 785-788.

40. Novak AJ, Darce JR, Arendt BK, Harder B, Henderson K, Kindsvogel W, Gross JA, Greipp PR,Jelinek DF (2004) Expression of BCMA, TACI, and BAFF-R in multiple myeloma: a mechanism for growth and survival. Blood 103(2): 689694. https://doi.org/10.1182/blood-2003-06-2043

41. Thompson, Jeffrey, S., Bixler, Sarah, A., Fang, Qian, Vora, Kalpit (2001) BAFF-R a Newly Identified TNF Receptor That Specifically Interacts with BAFF. Science 293(5537): 2108-2108.

42. Liu Y, Xu L, Opalka N, Kappler J, Shu HB,Zhang G (2002) Crystal Structure of sTALL-1 Reveals a Virus-like Assembly of TNF Family Ligands. Cell 108(3): 383-394.

43. Bossen C, Cachero TG, Tardivel A, Ingold K, Willen L, Dobles M, Scott ML, Maquelin A, Belnoue E,Siegrist CA (2008) TACI, unlike BAFF-R, is solely activated by oligomeric BAFF and APRIL to support survival of activated B cells and plasmablasts. Blood 111(3): 1004-1012.

44. Cachero TG, Schwartz IM, Qian F, Day ES, Bossen C, Ingold K, Tardivel A, Krushinskie D, Eldredge J,Silvian L (2006) Formation of virus-like clusters is an intrinsic property of the tumor necrosis factor family member BAFF (B cell activating factor). Biochemistry 45(7): 2006-2013.

45. Furie R, Stohl W, Ginzler EM, Becker M, Mishra N, Chatham W, Merrill JT, Weinstein A, McCune WJ, Zhong J, Cai W, Freimuth W,Belimumab Study G (2008) Biologic activity and safety of belimumab, a neutralizing anti-B-lymphocyte stimulator (BLyS) monoclonal antibody: a phase I trial in patients with systemic lupus erythematosus. Arthritis Res Ther 10(5): R109. https://doi.org/10.1186/ar2506

46. Sifuentes Giraldo WA, García Villanueva MJ, Boteanu AL, Lois Iglesias A,Zea Mendoza AC (2012) New Targets in Systemic Lupus (Part 2/2). Reumatología Clínica (English Edition) 8(5): 263-269. https://doi.org/10.1016/j.reumae.2012.08.002

47. Baker KP, Edwards BM, Main SH, Choi GH, Wager RE, Halpern WG, Lappin PB, Riccobene T, Abramian D,Sekut L (2010) Generation and characterization of LymphoStat-B, a human monoclonal antibody that antagonizes the bioactivities of B lymphocyte stimulator. Arthritis Rheum 48(11): 3253-3265.

48. Halpern WG, Lappin $\dagger$ P, Zanardi $\uparrow$ T, Cai W, Corcoran M, Zhong J, Baker,P. K (2006) Chronic administration of belimumab, a BLyS antagonist, decreases tissue and peripheral blood B-lymphocyte populations in cynomolgus monkeys: pharmacokinetic, pharmacodynamic, and toxicologic effects. Toxicological Sciences (2): 586-599.

49. Babini A, Cappuccio AM, Caprarulo C, Casado G, Eimon A, Figueredo H, Garcia MA, Magri S, Mannucci P, Perez Rodriguez S, Pons-Estel BA, Velozo EJ, Iglesias-Rodriguez M,Streger G (2020) Evaluation of belimumab treatment in patients with systemic lupus erythematosus in a clinical practice setting: Results from a 24-month OBSErve study in Argentina. Lupus 29(11): 1385-1396. https://doi.org/10.1177/0961203320947814

50. Guzman M,Hui-Yuen JS (2020) Management of Pediatric Systemic Lupus Erythematosus: Focus on Belimumab. Drug Des Devel Ther 14: 2503-2513. https://doi.org/10.2147/DDDT.S216193

51. Kraaij T, Arends EJ, van Dam LS, Kamerling SWA, van Daele PLA, Bredewold OW, Ray A, Bakker JA, Scherer HU, Huizinga TJW, Rabelink TJ, van Kooten C,Teng YKO (2021) Long-term effects of combined B-cell immunomodulation with rituximab and belimumab in severe, refractory systemic lupus erythematosus: 2-year results. Nephrol Dial Transplant 36(8): 1474-1483. https://doi.org/10.1093/ndt/gfaa117 

DA (2021) 10 Years of belimumab experience: What have we learnt? Lupus: 9612033211028653. https://doi.org/10.1177/09612033211028653

53. Lokhandwala T, Yue B, Coutinho AD,Bell CF (2021) Within-trial economic analysis of flare data from the BLISS-SC trial of subcutaneous belimumab in systemic lupus erythematosus. Lupus Sci Med 8(1). https://doi.org/10.1136/lupus-2020$\underline{000438}$

54. Muller P, Chowdhury K, Gordon C, Ehrenstein MR,Dore CJ (2020) Safety and efficacy of belimumab after B cell depletion therapy in systemic LUPUS erythematosus (BEAT-LUPUS) trial: statistical analysis plan. Trials 21(1): 652. https://doi.org/10.1186/s13063-020-04391-2

55. Petricca L, Gigante MR, Paglionico A, Costanzi S, Vischini G, Di Mario C, Varriano V, Tanti G, Tolusso B, Alivernini S, Grandaliano G, Ferraccioli G,Gremese E (2020) Rituximab Followed by Belimumab Controls Severe Lupus Nephritis and Bullous Pemphigoid in Systemic Lupus Erythematosus Refractory to Several Combination Therapies. Front Med (Lausanne) 7: 553075. https://doi.org/10.3389/fmed.2020.553075

56. Bag-Ozbek A,Hui-Yuen JS (2021) Emerging B-Cell Therapies in Systemic Lupus Erythematosus. Ther Clin Risk Manag 17: 39-54. https://doi.org/10.2147/TCRM.S252592

57. Cheng H, Zhao CS, Yan CL, Gao C,Wen HY (2021) Efficacy of Belimumab for refractory systemic lupus erythematosus (SLE) involving the central nervous system. Eur J Intern Med. https://doi.org/10.1016/j.ejim.2021.06.012

58. Petar L,Aleksander L (2015) Current and emerging treatment options for ANCA-associated vasculitis: potential role of belimumab and other BAFF/APRIL targeting agents. Drug Design Development \& Therapy 9: 333.

59. Furie R, Petri M, Zamani O, Cervera R, Wallace DJ, Tegzová D, Sanchezguerrero J, Schwarting A, Merrill JT,Chatham WW (2011) A phase III, randomized, placebo-controlled study of belimumab, a monoclonal antibody that inhibits B lymphocyte stimulator, in patients with systemic lupus erythematosus. Arthritis \& Rheumatism 63(12): 3918-3930.

60. Stohl W, Hiepe F, Latinis K, Thomas M, Scheinberg M, Clarke A, Aranow C, Wellborne F, Mendoza C, Hough D, Pineda L, Migone T, Zhong Z, Freimuth W,Chatham W (2014) Belimumab reduces autoantibodies, normalizes low complement levels, and reduces select B cell populations in patients with systemic lupus erythematosus. Arthritis \& Rheumatology 64(7): 2328-2337.

61. Isenberg DA, Petri M, Kalunian K, Tanaka Y, Urowitz MB, Hoffman RW, Morgan-Cox M, Iikuni N, Silk M,Wallace DJ (2016) Efficacy and safety of subcutaneous tabalumab in patients with systemic lupus erythematosus: results from ILLUMINATE-1, a 52-week, phase III, multicentre, randomised, double-blind, placebo-controlled study. Ann Rheum Dis 75(2): 323-331. https://doi.org/10.1136/annrheumdis-2015-207653

62. Komocsar WJ, Blackbourne JL, Halstead CA, Winstead CJ,Wierda D (2016) Fully human anti-BAFF inhibitory monoclonal antibody tabalumab does not adversely affect T-dependent antibody responses in cynomolgus monkey (Macaca fasicularis): A summary of three pre-clinical immunotoxicology evaluations. J Immunotoxicol 13(1): 7-19. https://doi.org/10.3109/1547691X.2014.994793

63. Genovese M, Fleischmann R, Greenwald M, Satterwhite J,Benichou O (2013) Tabalumab, an anti-BAFF monoclonal antibody, in patients with active rheumatoid arthritis with an inadequate response to TNF inhibitors. Annals of the Rheumatic Diseases 72(9): 1461-1468.

64. Ng LG, Mackay CR,Mackay F (2005) The BAFF/APRIL system: life beyond B lymphocytes. Molecular Immunology 42(7): 763-772.

65. Yu G, Boone T, Delaney J, Hawkins N, Kelley M, Ramakrishnan M, Mccabe S, Qiu WR, Kornuc M,Xia XZ (2000) APRIL and TALL-I and receptors BCMA and TACI: system for regulating humoral immunity. Nature Immunology 1(3): 252-256.

66. Baker D, Pryce G, James LK, Schmierer K, Giovannoni G (2020) Failed B cell survival factor trials support the importance of memory B cells in multiple sclerosis. Eur J Neurol 27(2): 221-228. https://doi.org/10.1111/ene.14105

67. Cerutti DS, Duke R, Freddolino PL, Fan H,Lybrand TP (2008) Vulnerability in Popular Molecular Dynamics Packages Concerning Langevin and Andersen Dynamics. Journal of chemical theory and computation 4(10): 1669.

68. Cave RJ,Newton M (1997) Calculation of electronic coupling matrix elements for ground and excited state electron transfer reactions: Comparison of the generalized Mulliken-Hush and block diagonalization methods. Journal of Chemical Physics 106(22): 9213-9226. 
69. Essmann U, Perera L, Berkowitz ML, Darden T, Lee H,Pedersen LG (1995) A smooth particle mesh Ewald method. Journal of Chemical Physics 103(19): 8577-8593.

70. Jian S, Jing W, Wang Y, Xuan L,Fu X (2015) Molecular Mechanism of the Affinity Interactions between BAFF and Its Peptides by Molecular Simulations. Protein \& Peptide Letters 22(11): -.

71. Onufriev A, Bashford D,Case DA (2010) Exploring protein native states and large-scale conformational changes with a modified generalized born model. Proteins-structure Function \& Bioinformatics 55(2).

72. Hou T, Wang J, Li Y,Wang W (2011) Assessing the Performance of the MM/PBSA and MM/GBSA Methods. 1. The Accuracy of Binding Free Energy Calculations Based on Molecular Dynamics Simulations. Journal of Chemical Information \& Modeling 51(1): 69-82.

73. Fu X, Mao Z, Li S, Guan Y, Jian X, Sun J,Wei J (2017) Molecular mechanism of the selectivity between BAFF/APRIL and their receptors by molecular simulations. Molecular Simulation 43(8): 590-598. https://doi.org/10.1080/08927022.2017.1279281

74. Li L, Jiang Y, Su L, Feng D, Wei J,Sun J (2020) Study on the Mechanism of Selective Interaction of BR3 and BCMA with BAFF and APRIL. Protein Pept Lett 27(11): 1114-1123. https://doi.org/10.2174/0929866527666200413101757

75. Shin W, Lee HT, Lim H, Lee SH, Son JY, Lee JU, Yoo KY, Ryu SE, Rhie J, Lee JY,Heo YS (2018) BAFF-neutralizing interaction of belimumab related to its therapeutic efficacy for treating systemic lupus erythematosus. Nat Commun 9(1): 1200. https://doi.org/10.1038/s41467-018-03620-2 


\section{FIGURE LEGENDS:}

Fig. 1 Time dependence of RMSD values along the MD trajectories for the complex of BAFF and belimumab, the heavy chain of belimumab is shown in red, the light chain of belimumab is shown in blue, and BAFF is shown in black

Fig. 2 Protein-protein docking schematic and interaction analysis of BAFF-belimumab complex for a the view of protein-protein docking schematic and interaction analysis of BAFF and the heavy chain of belimumab, $\mathbf{b}$ the view of protein-protein docking schematic and interaction analysis of BAFF and the light chain of belimumab, tan: BAFF, sky blue: heavy chain of belimumab, plum: light chain of belimumab, amino acid contacts in $0.5 \mathrm{~nm}$ were indicated, hydrogen bond was shown in blue straight line, the name and number of the interactive amino acids on BAFF and both chains of belimumab were also indicated

Fig. 3 Decomposition analyses for belimumab heavy chain (blue), belimumab light chain (yellow) and BAFF (grey)

Fig. 4 Protein-protein docking schematic and interaction analysis of BAFF-tabalumab complex, tan: BAFF, sky blue: heavy chain of belimumab, plum: light chain of belimumab, amino acid contacts in $0.5 \mathrm{~nm}$ were indicated, hydrogen bond was shown in blue straight line, the name and number of the interactive amino acids on BAFF and both chains of belimumab were also indicate

Fig. 5 The comparison of protein-protein docking schematic between BAFF-tabalumab complex and BAFF-belimumab complex for $\mathbf{a}$ the section included in the red square was the steric hindrance between the light chain of belimumab and the adjacent BAFF trimer after the combination of belimumab and BAFF, $\mathbf{b}$ the section included in the red square was the DxL motif where belimumab, tabalumab and BR3 binding and acting with BAFF, $\mathbf{c}$ the interaction between Y30 of belimumab light chain and L83 of BAFF, tan: local structure of BAFF60-mer, sky blue: heavy chain of belimumab, plum: light chain of belimumab, light green: tabalumab, red: the nature receptor of BAFF (BR3), the section included in the red square was the steric hindrance between the light chain of belimumab and the adjacent BAFF trimer after the combination of belimumab and BAFF

Fig. 6 The alignment result for both light chain and heavy chain of belimumab and tabalumab for a the alignment result of light chain, b The alignment result of heavy chain, the section included in the yellow square was the CDR1/2/3 of belimumab and tabalumab according to the label, the section included in the yellow square was the DxL motif 
Fig. 1

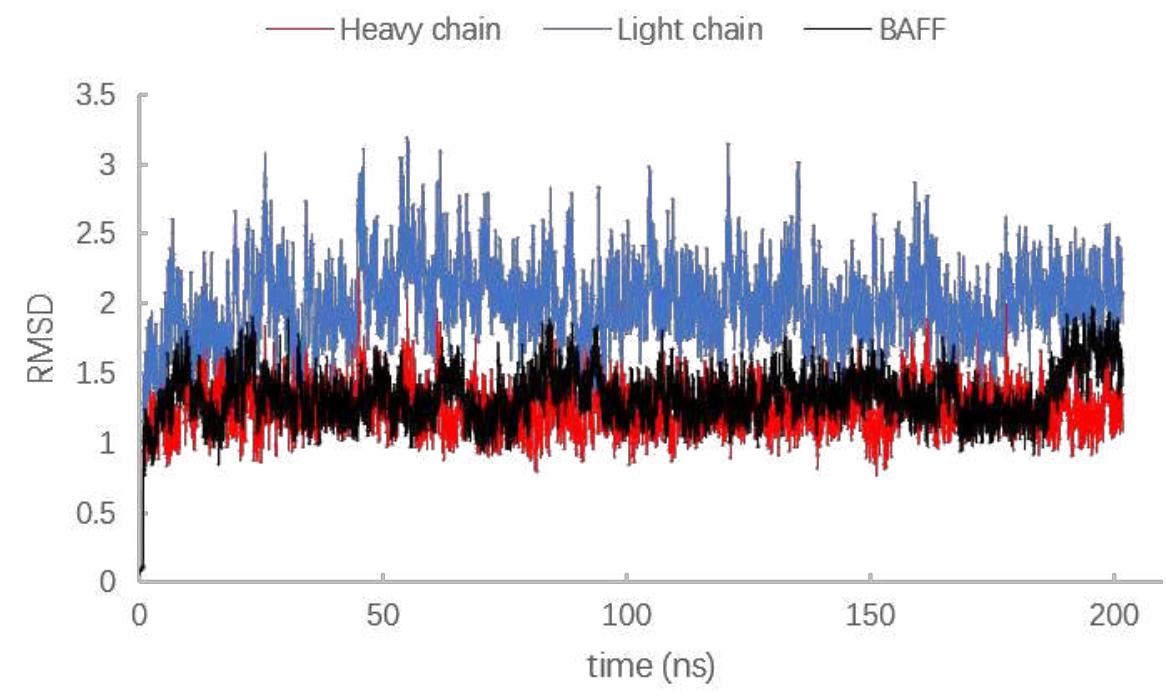


Fig. 2

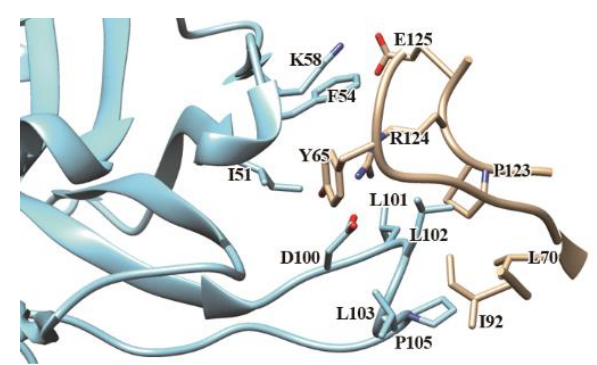

A

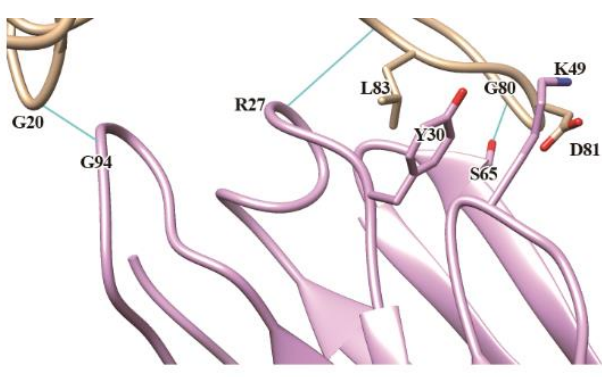

B 
Fig. 3

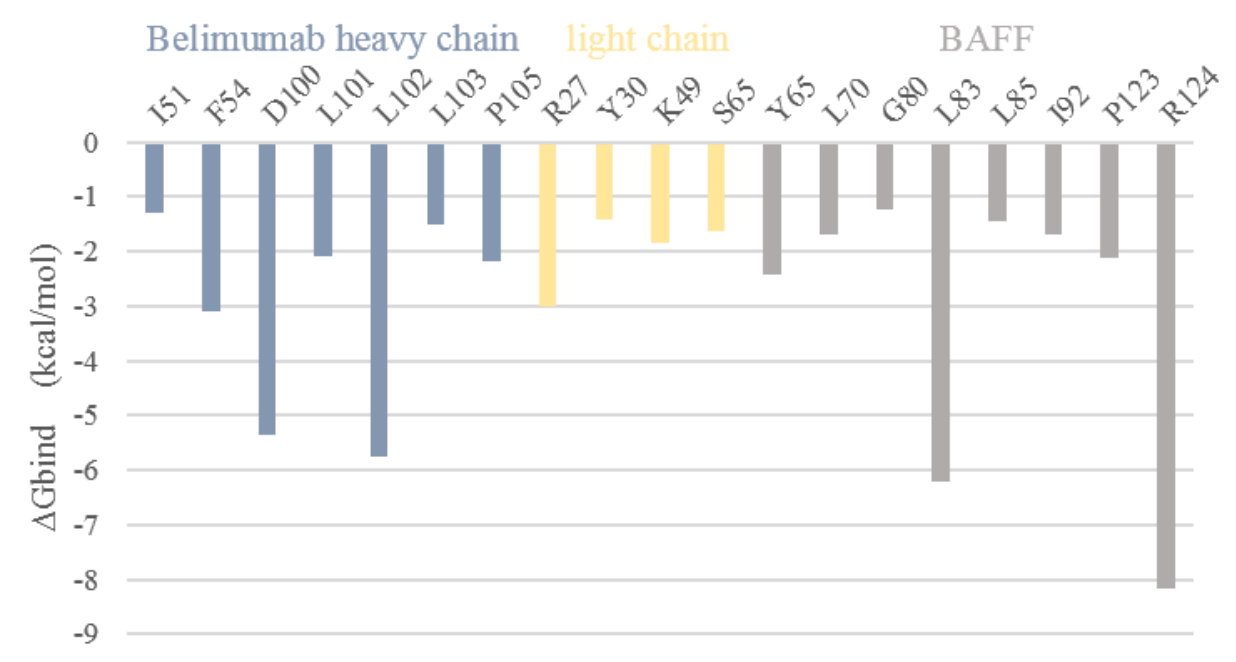


Fig. 4

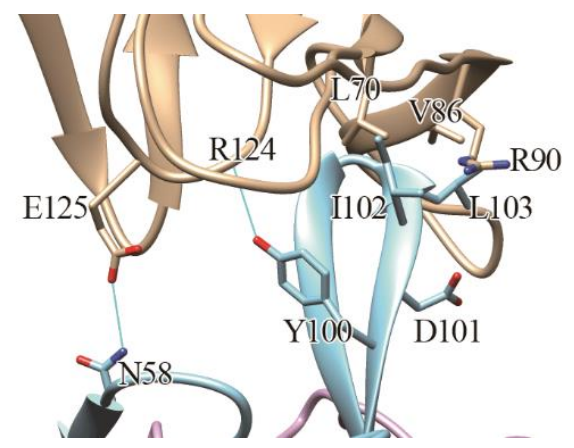


Fig. 5

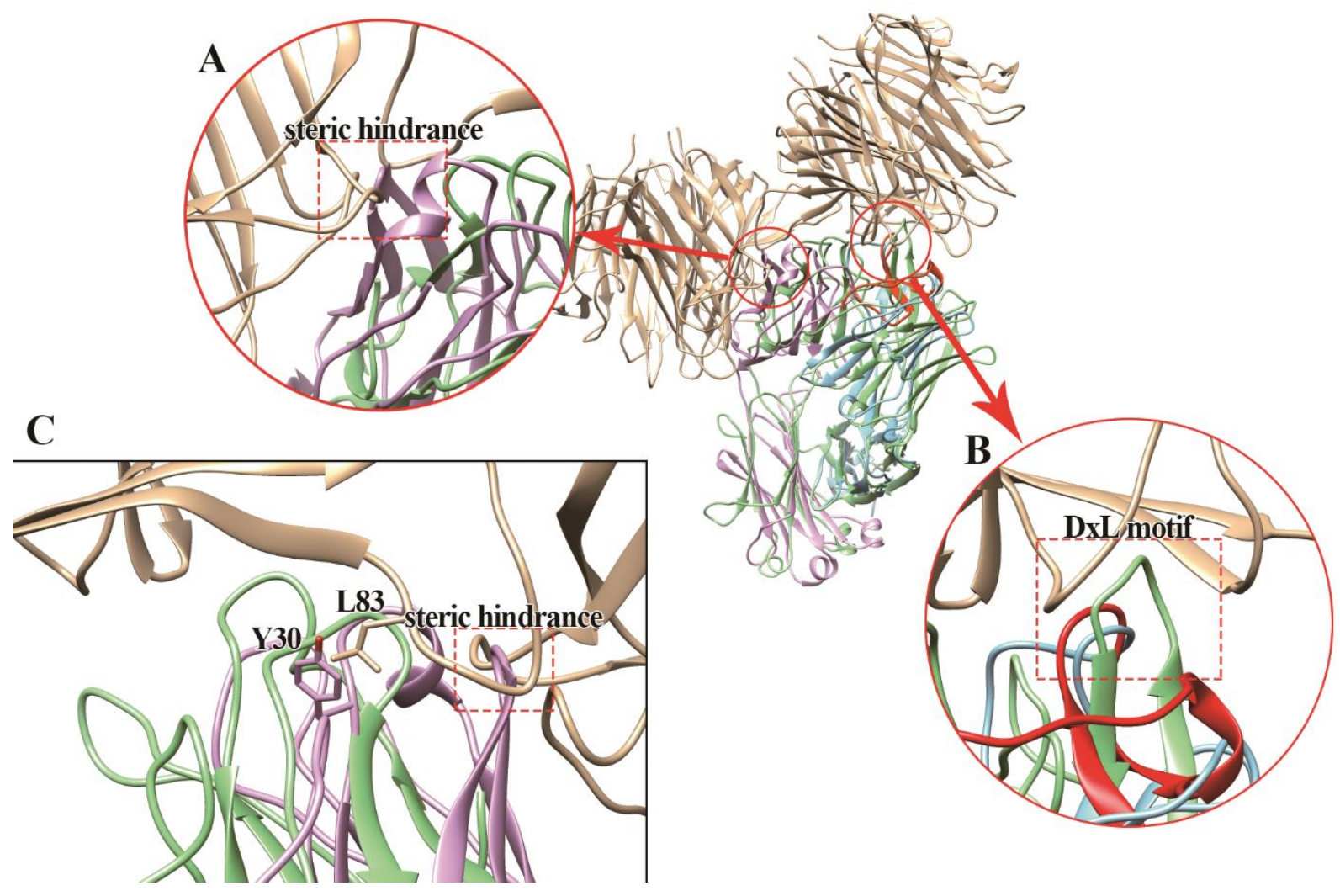


Fig. 6

A Belimumab SSELTQDPA-VSYALGQTVRVTC2GDSLRSYYASWYQQRPGQAPVLYIYGKNNRPSGIPDRF SGSSSGNTASLTITGAQA 79 Tabalumab EIVLTQSPATLSLSPGERATLSCRASDSVSRYLAYYYQRPGQAPRLLIYDASYRATGIPARF SGSGSGTDSTLTISSLEP 80 CDR1 CDR2

Belimumab EDEADYYCSSRDSSGNHIII-YFGGGTELTVLGQPRAAPSVILFPPSSEELQANKATLVLLISDFYPGAVTVANRADSSPV 157 Tabalumab EDFAVYYCQR----SNYPRTI GQGTKVEIK-RTVAAPSVFIFPPSDEQLKSGTASWYCLLNNFYPREAKVQWYVDNALQ 155 CDR3

Belimumab RAGYETTTPSKQS-NNKYAASSYLSLTPEQUYSHRSYSCQVTHEG--STVERTVAPTECS 214

Tabalumab SGNSQESVTEQDSRDSTYSLSNTLTLSKADYEKHKYYACEVTHQGLSSPVTRSFNRGEC- 214 light chain

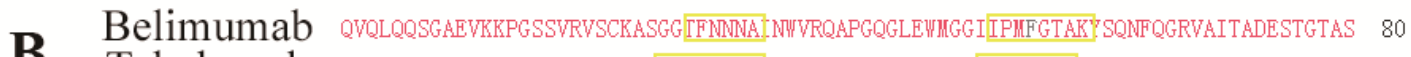

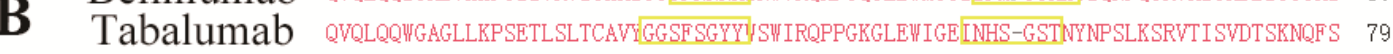

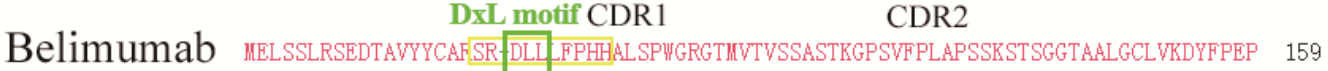

Tabalumab LRLSSVTAADTAYYYCARGY DIL GGYYYYFDYIGGGTLVTVSSASTKGPSYFPLAPCSRSTSESTAALGCLVKDYFPEP 159 CDR3

Belimumab VTVSWNSGALTSGVHTFPAVLQSSGLYSLSSWVTVPSSSLGTQTYICNNNHKPSNTKVDKRVEPRSCDRTHHHHH---- 235

Tabalumab vTVSWNSGALTSGVHTFPAVLQSGGLYSLSSWVTVPSSLGTRTYTCNVDHKPSNTKVDRRVES--------YGPPC 229

Belimumab

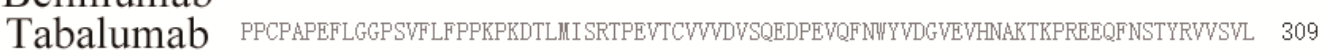

Belimumab

Tabalumab TVLHoDYLNGGEYKCKVSNKGLPSSIEKTISKAKGQPREPQWYTLPPSQEEHTKNOYSLTCLVKGFYPSDIAVEYESNGQ 389

Belimumab

Tabalumab PENNYRTTPPVLDSDGSFFLYSRLTVDRSRYOEGNVFSCSVIHEALEHNHYTQRSLSLSLGK 450 heavy chain 
Tables:

Table 1 The binding free energies of the BAFF-belimumab complex ( $\mathrm{kcal} / \mathrm{mol})$

\begin{tabular}{ccccccccc}
\hline \multirow{2}{*}{ Component* } & \multicolumn{2}{c}{ Complex } & \multicolumn{2}{c}{ BAFF } & \multicolumn{2}{c}{ Belimumab } & \multicolumn{2}{c}{ Delta } \\
\cline { 2 - 8 } & Mean & STD. & Mean & STD. & Mean & STD. & Mean & STD. \\
\hline$E_{\text {vdw }}$ & -4317.95 & 26.25 & -3153.03 & 20.69 & -1073.85 & 11.75 & -91.07 & 6.11 \\
$E_{\text {ele }}$ & -40584.57 & 101.12 & -29863.14 & 92.27 & -10345.54 & 43.09 & -375.89 & 18.17 \\
$E_{\text {int }}$ & 0 & 0 & 0 & 0 & 0 & 0 & 0 & 0 \\
$G_{\text {polar }}$ & -5867.00 & 74.46 & -4236.61 & 76.49 & -2061.96 & 36.20 & 431.57 & 14.1 \\
$G_{N P}$ & 180.05 & 2.36 & 138.72 & 1.74 & 54.62 & 0.82 & -13.29 & 0.55 \\
$E_{M M}$ & -44902.52 & 99.74 & -33016.17 & 89.87 & -11419.39 & 41.77 & -466.96 & 15.65 \\
$G_{\text {sol }}$ & -5686.95 & 73.44 & -4097.89 & 76.00 & -2007.34 & 36.12 & 418.28 & 14.04 \\
Total & -50589.47 & 63.97 & -37114.06 & 52.17 & -13426.73 & 28.69 & -48.68 & 4.09 \\
\hline
\end{tabular}

$* E_{v d w}$ : the van der Waals contribution from molecular mechanics; $E_{e l e}$ : the electrostatic energy as calculated by the molecular mechanics force field; $G_{\text {polar }}$ : the electrostatic energy to the solvation free energy; $G_{N P}$ : the energy of nonpolar components contributing to the solvation free energy; $E_{M M}$ : the free energy of the complex in vacuum which equals to $E_{v d w}, E_{\text {ele }}$ and $E_{\text {int }} ; G_{\text {sol }}$ : the free energy of the complex in solvation states which equals to $G_{p o l a r}$ and $G_{N P}$; Total: the whole binding free energy including $E_{M M}$ and $G_{s o l}$; Delta: the sum of BAFF and belimumab minus complex 
Table 2 The comparison of binding energies between belimumab-BAFF complex and BCMA-BAFF complex (kcal/mol)

\begin{tabular}{ccc}
\hline Energy & Belimumab-BAFF & BCMA-BAFF \\
\hline$\Delta E_{\text {vdw }}$ & -91.07 & -63.96 \\
$\Delta E_{\text {ele }}$ & -375.89 & -94.23 \\
$\Delta E_{\text {int }}$ & 0 & 0 \\
$\Delta G_{\text {polar }}$ & 431.57 & 123.09 \\
$\Delta G_{N P}$ & -13.29 & -10.13 \\
$\Delta E_{M M}$ & -466.96 & -158.19 \\
$\Delta G_{\text {sol }}$ & 418.28 & 112.96 \\
$\Delta G_{\text {bind }}$ & -48.68 & -45.23 \\
\hline
\end{tabular}


Table 3 The computational alanine scanning results of the key residues for the BAFF-belimumab complex ( $\mathrm{kcal} / \mathrm{mol})$

\begin{tabular}{|c|c|c|c|c|c|c|c|}
\hline Residue (chain) & $\Delta \Delta G_{v d w}$ & $\Delta \Delta G_{\text {ele }}$ & $\Delta \Delta G_{\text {polar }}$ & $\Delta \Delta G_{N P}$ & $\Delta \Delta G_{M M}$ & $\Delta \Delta G_{\text {sol }}$ & $\Delta \Delta G_{\text {bind }}$ \\
\hline I51 (heavy chain) & 1.75 & -0.14 & 8.53 & 0.23 & 1.61 & 8.75 & 1.29 \\
\hline F54 (heavy chain) & 4.9 & 2.7 & 4.23 & 0.75 & 7.6 & 4.97 & 3.49 \\
\hline D100 (heavy chain) & -2.2 & 37.1 & -4.61 & 0.28 & 34.9 & -4.33 & 21.48 \\
\hline L101 (heavy chain) & 2.56 & 0.68 & 6.71 & 0.40 & 3.25 & 7.11 & 10.36 \\
\hline L102 (heavy chain) & 8.18 & 0.04 & 5.26 & 1.05 & 8.21 & 6.3 & 5.43 \\
\hline L103 (heavy chain) & 1.94 & 0.28 & 7.14 & 0.27 & 2.22 & 7.41 & 9.64 \\
\hline R27 (light chain) & 2.89 & 34.02 & -27.88 & 0.35 & 36.91 & -27.54 & 0.29 \\
\hline Y30 (light chain) & 2.77 & -2.72 & 11.82 & 0.41 & 0.05 & 12.23 & 3.19 \\
\hline K49 (light chain) & 0.74 & 129.16 & -119.1 & 0.67 & 129.9 & -118.44 & 2.37 \\
\hline S65 (light chain) & 0.12 & 3.25 & 9.07 & 0.15 & 3.36 & 9.22 & 3.50 \\
\hline Y65 (BAFF) & 7.04 & 2.55 & 5.01 & 1.04 & 9.58 & 6.05 & 6.55 \\
\hline L70 (BAFF) & 2.76 & 0.1 & 7.71 & 0.37 & 2.85 & 8.08 & 1.85 \\
\hline L83 (BAFF) & 7.15 & -0.46 & 6.42 & 0.84 & 6.68 & 7.26 & 4.86 \\
\hline L85 (BAFF) & 1.51 & 0.27 & 7.79 & 0.21 & 1.78 & 7.99 & 0.69 \\
\hline I92 (BAFF) & 2.12 & -0.07 & 7.95 & 0.35 & 2.05 & 8.3 & 1.26 \\
\hline R124 (BAFF) & 1.22 & 35.35 & -14.13 & 3.31 & 36.57 & -10.83 & 16.66 \\
\hline E125 (BAFF) & 0.85 & 120.52 & -110.97 & 0.55 & 121.37 & -110.43 & 1.86 \\
\hline
\end{tabular}

$\Delta \Delta G_{\text {bind }}=\Delta G_{\text {bind }}($ alanine mutant $)-\Delta G_{\text {bind }}($ wild type $)$

$\Delta \Delta G_{\text {bind }}=\Delta \Delta G_{M M}+\Delta \Delta G_{\text {sol }}$

$\Delta \Delta G_{M M}=\Delta \Delta G_{\text {ele }}+\Delta \Delta G_{v d w}+\Delta \Delta G_{\text {int }}$

$\Delta \Delta G_{\text {sol }}=\Delta \Delta G_{\text {polar }}+\Delta \Delta G_{N P}$ 


\section{Supplementary Files}

This is a list of supplementary files associated with this preprint. Click to download.

- GraphicalAbstract.tif 